\title{
Assessment of Effectiveness of Clonidine and Atenolol in Providing Optimal Surgical in Nasal Surgery: A Clinical Study
}

\author{
Sandeep Kumar ${ }^{1 *}$, Abha Kumari² \\ ${ }^{1 * A s s i s t a n t ~ P r o f e s s o r, ~ D e p a r t m e n t ~ o f ~ E N T, ~}$ \\ ${ }^{2}$ Assistant Professor, Department of Pharmacology, \\ Rajendra Institute of Medical Sciences, Bariatu, Ranchi, Jharkhand, India.
}

\begin{abstract}
Background: Although adequate level of anaesthesia is achieved by various anaesthetic solutions, tachycardia, hypertension and other cardiovascular responses usually occur following nasal speculum insertion due to failure of gaining the adequate hemodynamic response. A reduction in the hemodynamic response to noxious stimulus has been shown by the preoperative use of clonidine (a-2 agonist) and atenolol ( $\beta$-blocker) at various stages of surgery. Hence, we evaluated and compared the efficacy of oral clonidine and oral atenolol when given pre-surgically in the patients undergoing nasal surgeries.
\end{abstract}

Materials \& Methods: The present study was conducted in the department of ENT and surgery of the medical institution and included 120 patients who underwent rhinoplasty, septoplasty, and functional endoscopic sinus surgery. All the patients were randomly divided into two study groups. First group included patients who received oral atenolol while other group included patients who received oral clonidine before induction of anaesthesia. All the clinical and hemodynamic parameters of the patients were assessed pre-surgically and during the surgery. Post-operative assessment of the hemodynamic parameters was also done. At the end of study decoding of groups and the data compilation was done. All the results were analyzed by SPSS software.

Results: The mean age of the patients in the two study groups was 28.5 and 32.5 years respectively. 70 percent of the patients in the oral atenolol group were males while in oral

\section{INTRODUCTION}

One of the preferred procedures for treating small pituitary tumours is the Sublabial rhinoseptal trans-sphenoid approach. Despite adequate depth of anaesthesia, tachycardia, hypertension and other cardiovascular responses usually occur following nasal speculum insertion due to failure of gaining the adequate hemodynamic response. ${ }^{1}$ Microscopic details of the sellar region is obscured by intense bleeding due to this varied negative hemodynamic response. ${ }^{2}$ A reduction in the hemodynamic response to noxious stimulus have been shown by the preoperative use of clonidine ( $\alpha-2$ agonist) and atenolol ( $\beta$ blocker) at various stages of surgery. ${ }^{3,4}$ Hence, we evaluated and compared the efficacy of oral clonidine and oral atenolol when given pre-surgically in the patients undergoing nasal surgeries. clonidine group, 75 percent were males. Mean duration of the surgery in oral atenolol group and oral clonidine group was 119.70 and 121.50 minutes respectively. Non-significant results were obtained while comparing the $p$-value in between the two study groups for various demographic parameters. Significant difference was obtained while comparing the mean value of total blood loss in between the two study groups. Significant difference was obtained while comparing the quality.

Conclusion: Quality of surgical filed and amount of blood loss is comparatively less with the pre-surgical use of clonidine.

Key words: Atenolol, Clonidine, Nasal.

\section{${ }^{*}$ Correspondence to:}

Dr. Sandeep Kumar,

Assistant Professor, Department of ENT

Rajendra Institute of Medical Sciences, Bariatu, Ranchi, Jharkhand, India.

\section{Article History:}

Received: 22-08-2016, Revised: 08-09-2016, Accepted: 15-09-2016

\begin{tabular}{|l|c|}
\hline \multicolumn{2}{|c|}{ Access this article online } \\
\hline $\begin{array}{l}\text { Website: } \\
\text { www.ijmrp.com }\end{array}$ & Quick Response code \\
\hline DOI: & \\
10.21276/ijmrp.2016.2.5.032 & \\
\hline
\end{tabular}

\section{MATERIALS \& METHODS}

The present study was conducted in the department of ENT and surgery of the medical institution and included 120 patients who underwent rhinoplasty, septoplasty, and functional endoscopic sinus surgery. All the patients aged between 18 years to 55 years. Ethical approval was taken from the institutional ethical committee and written consent was obtained from the patients after explaining them in written the entire research protocol. Patients with any other systemic disorder, any known drug allergy, history of any other major or minor surgery in the past six months were excluded from the present study. All the patients were randomly divided into two study groups. First group included patients who received oral atenolol while other group included patients who 
received oral clonidine before induction of anaesthesia. All the clinical and hemodynamic parameters of the patients were assessed pre-surgically and during the surgery. Post-operative assessment of the hemodynamic parameters was also done. During the intraoperative and postoperative period (upto $24 \mathrm{hrs}$ ) the occurrence of side effects like hypotension and bradycardia were noted. Hypotension defined as $20 \%$ decrease in systolic blood pressure from baseline and bradycardia less than $60 \mathrm{bpm}$; if occurred, were treated appropriately. At the end of study decoding of groups and the data compilation was done. All the results were analyzed by SPSS software. Chi square test was used for assessment of level of significance.

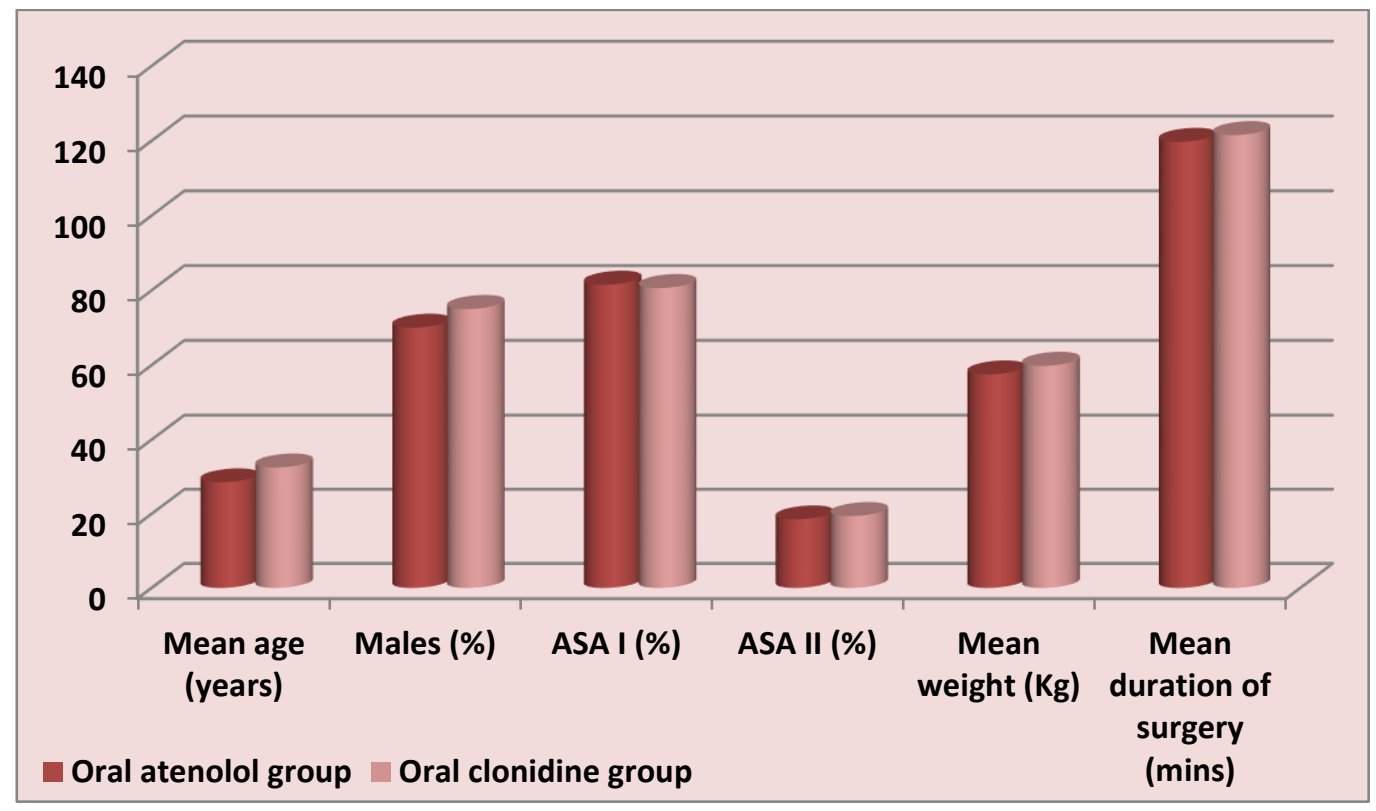

Graph 1: Demographic details of the patients

\section{RESULTS}

Graph 1 shows the demographic details of the patients. The mean age of the patients in the two study groups was 28.5 and 32.5 years respectively. 70 percent of the patients in the oral atenolol group were males while in oral clonidine group, 75 percent were males. Mean weight of the patients in oral atenolol group and oral clonidine group was 57.5 and $59.8 \mathrm{~kg}$ respectively. Mean duration of the surgery in oral atenolol group and oral clonidine group was 119.70 and 121.50 minutes respectively. Table 1 shows the $p$-value for various demographic details of the patients. Non- significant results were obtained while comparing the $p$-value in between the two study groups for various demographic parameters. Table 2 shows the $p$-value for comparison of oral blood loss in between the two study groups. Significant difference was obtained while comparing the mean value of total blood loss in between the two study groups. Table 3 highlights the p-value for comparison of quality if surgical field in between the two study groups. Significant difference was obtained while comparing the quality.

Table 1: $p$-value for various demographic details of the patients in the two study groups

\begin{tabular}{lccc}
\hline Parameter & Oral atenolol group & Oral clonidine group & $\mathrm{p}$-value \\
\hline Mean age (years) & 28.5 & 32.5 & 0.241 \\
Males (\%) & 70 & 75 & 0.418 \\
ASA I (\%) & 81.5 & 80.6 & 0.845 \\
ASA II (\%) & 18.5 & 19.4 & 0.794 \\
Mean weight (Kg) & 57.5 & 59.8 & 0.774 \\
Mean duration of surgery (mins) & 119.70 & 121.50 & 0.300 \\
\hline
\end{tabular}

Table 2: p-value for comparison of oral blood loss in between the two study groups

\begin{tabular}{cccc}
\hline Parameter & Oral atenolol group & Oral clonidine group & p-value \\
\hline Total blood loss $(\mathrm{ml})$ & 158.5 & 120.4 & $0.001^{*}$ \\
\hline$*$ : Significant & & &
\end{tabular}

Table 3: $p$-value for comparison of quality if surgical field in between the two study groups.

\begin{tabular}{lcccc}
\hline ACS Grading & \multicolumn{2}{c}{ End of surgery } & p-value \\
\cline { 2 - 3 } & Good & Fair & Poorer & $0.001^{*}$ \\
Oral atenolol group & 14 & 46 & 0 & $0.001^{*}$ \\
Oral clonidine group & 30 & 30 & 0 & 0.00 \\
\hline
\end{tabular}

Average Category Scale (ACS) Grading. 


\section{DISCUSSION}

Number of the patients undergoing various nasal surgical procedures due to pathologic and cosmetic reasons has increased in large number in the past few decades. ${ }^{5}$ Due to excessive bleeding during the surgery causing impairment of the visual field often results in the serious complications. ${ }^{6}$ Such complications can be avoided by either using a local anaesthesia, vasoconstrictors or performing the surgery under general anaesthesia. ${ }^{7}$ Due to discomfort associated with local anaesthesia, general anaesthesia is usually preferred for performing such surgeries. ${ }^{8}$ Immobile surgical field views along with respiratory tract protection are some of the advantages offered by the general anaesthesia. The effect of inhalational anaesthetic agents is potentiated by use of various drugs like beta blockers; alpha-2 agonists etc reduce the bleeding by virtue of inhibiting sympathetic stimulation. Literature quotes few studies assessing the effect of premedication with clonidine and atenolol on intrasurgical bleeding and the need for antihypertensive drugs. ${ }^{8,9}$ Hence, we evaluated and compared the efficacy of oral clonidine and oral atenolol when given presurgically in the patients undergoing nasal surgeries.

In the present study, we observed that in various surgical procedures, intra-operative blood loss was found to be comparatively less in patients with pre-medicated clonidine. Also, stable hemodynamic field was produced by both the drugs accompanied by a reduction in the bleeding leading to the optimal surgical field. This might be due to the fact that during surgical procedures, reduction and attenuation of the excitatory effect of sudden increased catecholamine/sympathetic stimulation occurs. Gupta et al compared and evaluated the effectiveness of presurgical delivery of clonidine and atenolol during trans-sphenoid pituitary resection in controlling the haemodynamic response. They evaluated 66 patients with age group of 18 to 65 years who underwent elective sublabial rhinoseptal trans-sphenoidal hypophysectomy. All the patients were divided randomly into three groups. First group comprised of patients who were given placebo, second and third group comprised of patients who were given tablet clonidine and tablet atenolol respectively. They observed non-significant change in the heart rate of the patients in the study group in comparison with the control group. Also in the control group, they observed a significant rise in the mean arterial pressure in comparison with the patients in the other two study groups. From the results, they suggested that in terms of efficacy, both the drugs are equally effective in patients undergoing elective sublabial rhinoseptal trans-sphenoidal hypophysectomy. ${ }^{10}$ Bajaj et al evaluated the efficacy of clonidine in reducing blood loss in pituitary adenoma surgery. They prospectively analyzed 50 patients with pituitary adenomas and randomly divided into two study groups. First group included patients that received clonidine orally, while other group included patients who placebo. They observed significant blood loss during surgery in between the patients of the two study groups. Also when compared between the two study groups, statistical significant results were obtained while comparing operative time and bleeding grading by the clinician. From the results, they concluded that in terms of efficacy and safety, clonidine is a safer drug in patients undergoing transsphenoidal microscopic pituitary adenoma surgeries. ${ }^{11}$ Matot et al evaluated and compared the effectiveness of two doses of oral clonidine premedication with placebo. They analyzed 62 patients and randomly divided them into two study groups. Only those patients were included that underwent elective fibreoptic bronchoscopy. They observed that during fibreoptic bronchoscopy, a significant increase in the blood pressure and heart rate were observed in the control group. From the result, they concluded that attenuated haemodynamic responses to fibreoptic bronchoscopy are observed with oral clonidine.12 Campagni et al evaluated oral clonidine and intravenous esmolol in blunting hemodynamic changes associated with intranasal injection of an epinephrine-containing local anesthetic solution during general anesthesia. They prospectively analyzed 61 patients undergoing endoscopic sinus and septoplasty surgery with general anesthesia. They observed no significant differences in sedation scores among the four treatment groups. From the results, they concluded that premedication with oral clonidine is effective in blunting the acute hemodynamic changes. ${ }^{13}$ Misra et al investigated that whether premedication with alpha2adrenoreceptor agonist clonidine, which also exhibits alpha1adrenoreceptor mediated vasoconstriction, would prevent or attenuate this fall in mean arterial pressure (MAP). They assessed 66 patients and randomly divided them into various study groups. They observed that in terms of heart rate, no significant alteration was observe in between the patients of the two study groups. From the results, they concluded that clonidine administered before induction of anesthesia attenuates the fall in MAP in patients undergoing craniotomy under isoflurane anesthesia. ${ }^{14}$

\section{CONCLUSION}

From the above result, the authors conclude that in terms of effectiveness and safety as well as in maintain the stability of hemodynamic profile of the patients, both clonidine and atenolol are equally effective. However, quality of surgical filed and amount of blood loss is comparatively less with the pre-surgical use of clonidine.

\section{REFERENCES}

1. Messick JM Jr, Laws ER Jr, Abboud CF. Anesthesia for transsphenoidal surgery of the hypophyseal region. Anesth Analg 1978;57:206-15.

2. Ali Z, Prabhakar H, Bithal PK, Dash HH. Bispectral indexguided administration of anesthesia for transsphenoidal resection of pituitary tumors: A comparison of 3 anesthetic techniques. J Neurosurg Anesthesiol 2009;21:10-5.

3. Traill R, Gillies R. Clonidine premedication for craniotomy: Effects on blood pressure and thiopentone dosage. J Neurosurg Anesthesiol 1993;5:171-7.

4. Chadha R, Padmanabhan V, Rout A, Waikar HD, Mohandas K. Prevention of hypertension during trans-sphenoidal surgery-the effect of bilateral maxillary nerve block with local anaesthetics. Acta Anaesthesiol Scand 1997;41:35-40.

5. Fromme GA, Mackenzie RA, Gould AB Jr, Lund BA, Offord KP (1986) Controlled hypotension for orthognathic surgery. Anesth Analg 65: 683-686.

6. Drozdowski A, Sieskiewicz A, Siemiatkowski A (2011) [Reduction of intraoperative bleeding during functional endoscopic sinus surgery]. Anestezjol Intens Ter 43: 45-50.

7. Mohseni M, Ebneshahidi A (2011) The effect of oral clonidine premedication on blood loss and the quality of the surgical field during endoscopic sinus surgery: a placebo-controlled clinical trial. J Anesth 25: 614-617. 
8. Marchal JM, Gómez-Luque A, Martos-Crespo F, Sánchez De La Cuesta F, Martínez-López MC, et al. (2001) Clonidine decreases intraoperative bleeding in middle ear microsurgery. Acta Anaesthesiol Scand 45: 627-633.

9. Anvari ZT, Fereydouniyan NF, Imani F, Sakhaei M, Alijani B, et al. (2012) Effect of clonidine remedication on blood loss in spine surgery. Anesth Pain 1: 252- 256.

10. Gupta D, Srivastava S, Dubey RK, Prakash PS, Singh PK, Singh U. Comparative evaluation of atenolol and clonidine premedication on cardiovascular response to nasal speculum insertion during trans-sphenoid surgery for resection of pituitary adenoma: A prospective, randomised, double-blind, controlled study. Indian J Anaesth. 2011 Mar;55(2):135-40.

11. Bajaj J, Mittal RS, Sharma A. Preoperative clonidine use in trans-sphenoidal pituitary adenoma surgeries - a randomized controlled trial. Br J Neurosurg. 2016 Aug 18:1-3.

12. Matot I, Kuras Y, Kramer MR. Effect of clonidine premedication on haemodynamic responses to fibreoptic bronchoscopy. Anaesthesia. 2000 Mar;55(3):269-74.

13. Campagni MA, Howie MB, White PF, McSweeney TD. Comparative effects of oral clonidine and intravenous esmolol in attenuating the hemodynamic response to epinephrine injection. $J$ Clin Anesth. 1999 May;11(3):208-15.
14. Misra S, Koshy T, Suneel PR. Oral clonidine attenuates the fall in mean arterial pressure due to scalp infiltration with epinephrine-lidocaine solution in patients undergoing craniotomy: a prospective, randomized, double-blind, and placebo controlled trial. J Neurosurg Anesthesiol. 2009 Oct;21(4):297-301.

\section{Source of Support: Nil.}

Conflict of Interest: None Declared.

Copyright: (c) the author(s) and publisher. IJMRP is an official publication of Ibn Sina Academy of Medieval Medicine \& Sciences, registered in 2001 under Indian Trusts Act, 1882.

This is an open access article distributed under the terms of the Creative Commons Attribution Non-commercial License, which permits unrestricted non-commercial use, distribution, and reproduction in any medium, provided the original work is properly cited.

Cite this article as: Sandeep Kumar, Abha Kumari. Assessment of Effectiveness of Clonidine and Atenolol in Providing Optimal Surgical in Nasal Surgery: A Clinical Study. Int J Med Res Prof. 2016; 2(5):156-59. 